\title{
A GALÁXIA DA INTERNET E SUA MULTIPLICIDADE DE USUÁRIOS/LEITORES: PRESSUPOSTOS PARA CONDUZIR UM ENSINO A DISTÂNCIA RECEPTIVO E ABRANGENTE
}

\author{
SÃO PAULO/SP MAIO/2018
}

\author{
Ana Cláudia Guimarães Antunes - Laureate - ana.c.g.antunes@gmail.com.br \\ Ana Paula Silva - UNIFACS - ana.paula@eadlaureate.com.br \\ Andrea Ortolani Faltin - Laureate - andrea.faltin@eadlaureate.com.br
}

Tipo: Investigação Científica (IC)

Natureza: Planejamento de Pesquisa

Categoria: Pesquisa e Avaliação

Setor Educacional: EDUCAÇÃO SUPERIOR

\begin{abstract}
RESUMO
Ao contextualizar o ensino a distância nas transformações sociais e comunicativas contemporâneas, este artigo tem como objetivo fornecer uma proposta de pesquisa para auxiliar na elaboração uma plataforma de ensino consiga atender diversos perfis de alunos de forma receptiva. Através de estudos sobre comunicação, parte-se do suposto de que o desenvolvimento dos meios de comunicação produz novas culturas e novas formas de leitura que não se excluem, mas geram novas camadas culturais. Como exemplo deste processo cumulativo, Lúcia Santaella estabelece quatro camadas que se dialogam: "ancestral (cultura oral), residual (cultura impressa), dominante (cultura de massas) e emergente (cultura participativa/[cibercultura])" (SANTAELLA, L. 2008, p.95).

Os meios de comunicação, principalmente a internet, são os mediadores da educação no ensino a distância. Neste sentido, as formas de uso dos meios de comunicação, as novas camadas culturais, os novos modos de leitura gerados transformam o processo educativo. Para assimilar a diversidade de usos e influências dos meios de comunicação é necessário partir da produção da cultura, ou seja, compreender o lugar social dos usuários/alunos do ensino a distância e suas produções de sentido.

Há, portanto, diversos desafios que a elaboração do ensino a distância enfrenta: seja porque há uma multiplicidade de perfis dos alunos que irão assimilar os conteúdos formais de diferentes maneiras, seja porque os alunos terão diferentes níveis de habilidades para acessar a internet. Através dos estudos sobre hospitalidade, a prática do ensino a distância incorpora caminhos metodológicos que facilitam o acolhimento e a formação deste conjunto heterogêneo de trajetórias socioculturais. O objetivo final desta proposta é dar fundamentação para a elaboração de um ambiente virtual acessível e um ensino que o auxilie a encontrar os melhores caminhos para a trajetória profissional dos alunos.
\end{abstract}

Palavras-chave: Comunicação; Ensino a distância; Hospitalidade; Cultura

AGRADECIMENTOS 


\section{Introdução e objetivos}

O crescimento exponencial dos cursos à distância no Brasil está inserido em uma conjuntura econômica, política e social específica. No entanto, dentro desta teia de relações que tem favorecido este crescimento, há uma linha importante que pretendemos traçar aqui e que revela que este tipo de ensino tende a se tornar cada vez mais consolidado nas instituições de ensino: o imenso desenvolvimento e expansão da internet como meio de comunicação, integração e interdependência mundial. Entendese que este desenvolvimento altera a economia, as habilidades exigidas no mercado de trabalho e, consequentemente, a própria elaboração e produção dos saberes.

Ao observar este processo amplo de transformação nas comunicações, chega-se à conclusão primordial de que a condução do ensino a distância tem se mostrado inexorável. Há uma miríade de teorias da comunicação que se debruçam sobre as consequências sociais do atravessamento dos meios de comunicação no nosso dia a dia. Parte-se do pressuposto de que algumas conclusões elaboradas por estes estudos servem como ponto de partida para se elaborar pesquisas e medidas que pensem 0 ensino a distância integrado e em diálogo com o seu meio social. Neste sentido, este texto visa, em primeiro lugar, contextualizar o ensino a distância nas transformações sociais e comunicativas contemporâneas.

Com esta reflexão, pretendemos, de forma mais específica, elaborar uma proposta de pesquisa para auxiliar na elaboração de futuras abordagens metodológicas que melhorem a comunicação com os alunos, estimulem a assimilação de conteúdos pedagógicos e construam habilidades necessárias a um cenário de gradativa e constante informatização de todo o mundo social. Segundo Pierre Levy, uma mudança relevante, no âmbito da construção de habilidades, é o fato de que há um "saber-fluxo", ou seja, um saber cuja aprendizagem não pode mais ser organizada de forma predefinida. Nas palavras do autor:

O saber-fluxo, o saber-transação de conhecimento, as novas tecnologias da inteligência individual e coletiva estão modificando profundamente os dados do problema da educação e da formação. O que deve ser aprendido não pode mais ser planejado, nem precisamente definido de maneira antecipada (...). Devemos construir novos modelos do espaço dos conhecimentos (LEVY, 1999, p.35)

O presente trabalho articula, a princípio, as reflexões sobre as novas formas de mediação da experiência inauguradas pelos meios de comunicação, sobretudo a internet, com as teorias da hospitalidade e sua contribuição para o desenvolvimento de 
práticas de acolhimento. Posteriormente, com base nesta reflexão, iremos apresentar um aporte para o desenvolvimento de pesquisas e metodologias que busquem um ensino a distância acessível, receptivo e abrangente. Este tipo de embasamento teórico se revela como fundamental para se compreender e aprimorar este processo educativo recente e em constante transformação.

\section{Referencial teórico}

Para compreender como os meios de comunicação afetam a experiência social e, em consequência, modificam a sociabilidade, os valores e a produção de conhecimento, é importante destacar dois âmbitos deste processo: em primeiro lugar, o fato de que os meios de comunicação sempre impulsionaram as principais experiências da modernidade, como, por exemplo, o desencaixe, uma noção desenvolvida por Anthony Giddens; em segundo lugar, 0 ato de assimilar as mensagens dos meios de comunicação, e as formas pelas quais eles são utilizados, é uma atividade situada socialmente, ocorrendo de formas distintas, dependendo do lugar social (classe social, país, cultura) de cada indivíduo.

O desencaixe significa, para este autor, um descolamento das relações sociais locais "e sua rearticulação através de partes indeterminadas do espaço-tempo" (GIDDENS, 2002, p.24). Esse processo de desencaixe se radicaliza com o uso da internet, seja no aspecto da ampliação da visão de mundo, seja nas possibilidades de liberdade e autonomia. Há, na verdade, a partir da criação da internet, uma mudança profunda na relação com os meios de comunicação, na elaboração e assimilação de conhecimentos e habilidades. Segundo Lucia Santaella, com a internet, "o receptor não está mais em posição de recepção clássica. A mensagem só toma todo o seu significado sob a sua intervenção. Ele se torna de certa maneira criador" (SANTAELLA, 2004. p. 162). Assim, há um novo contexto em que o emissor "não emite mais mensagens, mas constrói um sistema com rotas de navegação e conexões" (Idem, p.163).

Ou seja, com a internet, o receptor constitui parte importante no processo de emissão, enquanto que o emissor tem a função básica de construir e oferecer sistemas de navegação. Neste âmbito, Canclini contribui para pensar a diferença de consumo e uso da internet, ao avaliar que "o consumidor de televisão, da televisão pré-digital, era menos ativo do que o usuário de internet, que tem mais recursos para trabalhar na edição de materiais, interromper e selecionar, ir e voltar" (CANCLINI, 2008. p.52). Estas características demonstram que a internet é um meio de comunicação no qual as formas de uso implicam um repertório cultivado de informações, interesses e saberes, tanto fornecidos por uma educação formal como referentes ao acesso à tecnologia. 
Acrescente-se a isto o fato de que há uma tendência de que os modelos de computadores se tornam cada vez mais portáteis e, ao mesmo tempo, concentrem diversos equipamentos, tais como: televisão, telefone, câmera, console de jogos, entre outros. Estas transformações tendem a fazer da navegação na internet algo cada vez mais comum e dinâmico. Ou seja, em meio a todas essas mudanças, permanece o uso da internet. Concentrando-se neste viés de pensamento, Lúcia Santaella faz a seguinte análise:

Assim, o que deve permanecer, em meio a todas essas mudanças que virão, é aquilo que chamo de leitor imersivo. Mesmo que as interfaces mudem, o leitor imersivo continuará existindo, pois navegar significa movimentar-se física e mentalmente em uma miríade de signos, em ambientes informacionais e simulados (SANTAELLA, 2004, p.184).

A autora classifica como leitor imersivo aquele que "começa a emergir nos novos espaços incorpóreos da virtualidade" (Idem, p.19). A partir dos novos estímulos referentes à comunicação global, surge o leitor imersivo, que expressa, por sua vez, uma nova sensibilidade e uma nova forma de ler. Segundo Santaella, a leitura orientada hipermidiaticamente é uma atividade nômade, que vai de um lado para outro, junta fragmentos que se reúnem, estabelecendo uma lógica associativa e de mapas cognitivos personalizados e intransferíveis. Mais do que isso, é uma leitura que se torna também escritura, pois, na hipermídia, a mensagem só vai se estruturando na medida em que leitor-produtor a estabelece e a expressa (Idem, pp.174-175).

Desta forma, a mudança na percepção, nas formas de ler que a internet introduz, são profundas e, aparentemente, permanentes. No entanto, há outro âmbito desta transformação longamente debatido nos estudos sobre comunicação: as transformações na sociabilidade e nos valores diante da introdução da internet no cotidiano. Sobre isto, Manuel Castells faz a seguinte análise sobre a interação social pela internet:

Contrariando alegações de que a internet seria ou uma fonte de comunitarismo renovado ou uma causa de alienação do mundo real, a interação social na internet não parece ter um efeito direto sobre a configuração da vida cotidiana em geral, exceto por adicionar interação on-line às relações sociais existentes. (...) O estudo da sociabilidade na/sobre/com a Internet deve ser situado no contexto de transformações dos padrões de sociabilidade em nossa sociedade. Isso não significa menosprezar a importância do meio tecnológico, mas inserir seus efeitos específicos na evolução geral dos padrões de interação social e em sua relação com os suportes materiais dessa interação: espaço, organizações e tecnologias da comunicação (CASTELLS, 2003, pp.100-105). 
Castells destaca que a internet, como qualquer outro meio de comunicação, está inserida em uma rede que envolve tanto organizações, tecnologias, como atividades simbólicas e que, em consequência, o estudo dos seus efeitos na sociabilidade e no cotidiano deve levar em conta este contexto. Vale destacar, portanto, que a tecnologia está em constante mudança, o que tem como resultado, entre outras coisas, mudanças nas formas de usar os meios de comunicação. A diversidade de usos está associada, no entanto, à diversidade dos lugares sociais dos usuários.

A percepção do mundo social está atrelada ao habitus específico e, por consequência, às disposições culturais. Também no âmbito da recepção da mídia, cada disposição cultural levará a formas específicas de assimilação de mensagens e formas de uso de cada meio de comunicação, ou seja, a recepção e o uso da mídia é uma atividade situada. O espaço social é, segundo Bourdieu, desenhado de acordo com as diferenças que funcionam "simbolicamente como espaço dos estilos de vida" (BOURDIEU, 2001. p. 136). Assim, para Bourdieu, o espaço dos estilos de vida pode ser definido como o mundo social representado, que tem no habitus o definidor de diferenças e de geração de práticas. Nas palavras de Bourdieu, o mundo social representado é constituído "na relação entre as duas capacidades que definem o habitus, ou seja, capacidade de produzir práticas e obras classificatórias, além da capacidade de diferenciar e de apreciar essas práticas e esses produtos (gosto)" (BOURDIEU, 2007, p.237).

Nesse sentido, o habitus e o gosto estão na origem dos estilos de vida, que, em síntese, podem ser definidos por um conjunto de práticas distintivas que exprimem a mesma intenção expressiva. Tendo como ponto de partida a teoria de Bourdieu, parte-se do pressuposto de que há uma multiplicidade de perfis de alunos que, estando em diferentes lugares sociais, irão assimilar e ter aproveitamentos diferentes entre si dos conteúdos curriculares; apreender e fazer uso do ambiente virtual de diferentes formas; e, por fim, estabelecer diferentes planos e projetos de carreira. Neste sentido, para além do uso situado da mídia, é importante dizer que, no caso do ensino a distância, há a mediação da internet para a assimilação de todos estes elementos. Construir um ambiente virtual receptivo que direcione facilmente o aluno/usuário/leitor para encontrar as ferramentas, conteúdos e caminhos para a carreira se constitui como fundamental.

A hospitalidade, reconhecida comumente como o "bem receber", e muitas vezes relacionada somente ao universo comercial da hotelaria, é um termo que contempla um sentido mais abrangente, englobando a compreensão de um encontro/relação entre dois indivíduos: um dentro de seu ambiente, o que recebe, e o outro fora de seu espaço. A hospitalidade, entre suas muitas linhas, trata essencialmente de relações humanas, que estabelecem troca e reciprocidade como elementos primordiais de sociabilidade 
(CAMARGO, 2004).

Segundo Lashley et al. (2007), a hospitalidade pode ser concebida como um conjunto de comportamentos originários da própria base da sociedade, da mutualidade, reciprocidade e troca, relacionados ao senso de comunidade; e pode ser analisada através dos domínios social/cultural, privado/doméstico e comercial, que representam aspectos da oferta de hospitalidade de maneira independente e sobreposta.

Importante ressaltar que Camargo (2004) também aponta o ambiente virtual como espaço social para o desenvolvimento da hospitalidade e que a hospitalidade pode ser designada também mesmo às formas virtuais de contato humano (CAMARGO, 2015). Desta forma, esta hospitalidade consumida no ambiente comercial atende a uma função complexa, pois o consumo de produtos e serviços associados é usado como um meio de estabelecer e manter relações sociais (LASHLEY ET AL, 2007).

Utilizar conceitos teóricos dos estudos de Hospitalidade pode auxiliar na compreensão e desenvolvimento de ferramentas para uma melhor recepção e acolhimento dos alunos, principalmente por esta ser considerada um ritual básico do vínculo humano. Uma vez que a hospitalidade é baseada em um processo de comunicação interpessoal, que constitui fórmulas rituais que variam de acordo com o grupo social em que se está inserido, podendo resultar no desejo ou na recusa de vínculo (CAMARGO, 2004), o conhecimento do perfil do aluno se manifesta como recurso imprescindível para a construção de práticas de acolhimento que aproximem as ferramentas tecnológicas de comunicação e informação das habilidades e do acervo sociocultural do aluno.

\section{Procedimentos metodológicos}

Para elaborar estratégias de mediação que sejam receptivas, é necessário conhecer, a princípio, o lugar social dos alunos e, em consequência, seus repertórios de habilidades, suas preferências e metas. Tendo como pressuposto que o uso e recepção da mídia é uma atividade situada, se torna relevante produzir dados sobre os alunos (e potenciais alunos). A pesquisa quantitativa a ser conduzida, preferencialmente nos polos e elaborada a partir de surveys, deverá ter como temas: (a) Contexto social e econômico; (b) Valores culturais e capital simbólico; (c) Perfil de uso da internet; (d) Trajetória acadêmica e ambições.

Os dados devem ser tabulados e divididos com a intenção de estabelecer uma visão ampla da multiplicidade de perfis de alunos. Este perfil tem base teórico-metodológica a noção de habitus, desenvolvida por Pierre Bourdieu, que, como tratado no item 
referencial teórico, estabelece as disposições culturais estruturadas e estruturantes. $O$ aporte teórico-metodológico fornecido por Bourdieu permite que se compreenda a relação entre indivíduo e estruturas macrossociais (MONTAGNER, 2007).

O quadro amplo de perfis deve guiar um estudo para a divisão em grupos de alunos com trajetórias, necessidades e expectativas semelhantes. Nesse sentido, a prosopografia, construção de biografias coletivas que revelam trajetórias sociais comuns, torna-se um recurso metodológico importante para a construção de perfis de alunos (BULST, 2007). A partir da definição desta divisão, será possível a construção de estratégias para estabelecer as práticas pedagógicas mais adequadas e acolhedoras para cada perfil, bem como o melhor caminho para se chegar a ou para melhorar a posição do aluno no mercado de trabalho.

\section{Apresentação e discussão dos resultados}

Os resultados são preliminares, fruto das reflexões produzidas a partir da elaboração da proposta de pesquisa e de dados coletados através de uma análise exploratória. Um bom exemplo de aplicação de uma estratégia de acolhimento que, ao mesmo tempo, direciona o aluno a encontrar o que pode ser o melhor curso para o seu perfil é o Online Learning da Harvard Business School. Ao entrar no site da Instituição, você pode acessar, a princípio, dois caminhos: o primeiro grupo de cursos se destina a indivíduos que estão, sozinhos, buscando encontrar o melhor aperfeiçoamento para as suas carreiras; o outro grupo se destina a organizações que estão buscando aperfeiçoamento para os seus colaboradores. No grupo de curso para indivíduos, o site ainda convida os interessados a responder o que "melhor o descreve", estabelecendo três perfis:

1. Estudante: estou explorando diferentes carreiras. Quero ser competitivo no mercado de trabalho e agregar valor à minha empresa desde o primeiro dia.

2. Início de carreira: estou pronto para definir meu futuro. Eu posso estar pensando na escola de negócios ou em avançar no meu atual campo de atuação.

3. notar algumas pistas sobre como esta instituição Meio de carreira: eu me estabeleci. Estou procurando reforçar meus conhecimentos de negócios e ajustar minhas habilidades de liderança.

(Tradução

livre)

Disponível

em

:https://hbx.hbs.edu/? hstc=7599981.07430159d50a3c91e72c280a7921bf0d.14889312 $\underline{00074.1488931200075 .1488931200076 .1 \& \text { hssc }=7599981.1 .1488931200077 \& \text { hsfp }}$ $=528229161)$ 
Com este exemplo, já é possível notar algumas pistas sobre como esta instituição, uma das melhores do mundo no ensino superior, buscou estabelecer diferentes perfis de alunos para elaborar uma estratégia eficaz de ensino. Mais do que isto, esta estratégia demonstra a compreensão das necessidades do aluno e também a preocupação com o acolhimento deste aluno por meio de uma plataforma de ensino hospitaleira. No ambiente virtual de aprendizagem, o processo de relação interpessoal acontece dentro de um ritual que estabelece diferentes trocas. Neste cenário, é importante ressaltar que a plataforma utilizada pelo aluno pode facilitar ou minimizar estas relações de hospitalidade. Tanto as ferramentas que facilitem a compreensão do ambiente de aprendizagem ao qual o aluno é submetido, quanto ferramentas que proporcionem a interação com tutores, professores e colegas para desenvolvimento de trocas e vínculos, são importantes para o desenvolvimento de um ambiente hospitaleiro.

Outro exemplo, observado na instituição supracitada, que promove um ambiente hospitaleiro para o aluno, é uma página de informações e de descrição do funcionamento da plataforma de ensino utilizada, de modo que os alunos possam conhecê-la antes da compra dos cursos (acesso pelo link https://hbx.hbs.edu/learningplatforms/course-platform). Estas informações aumentam as chances de afinidade dos alunos com os recursos oferecidos, minimizando o aspecto hostil dos primeiros acessos, que podem acarretar em repulsa às interações virtuais futuras.

A descrição nesta página também ressalta a facilidade de interação entre colegas, e evidencia a importância das relações desenvolvidas durante o curso. Como pode ser observado no trecho a seguir, retirado da página descrita acima:

Quando você faz login na plataforma do curso HBX, entra na sua sala de aula on-line. [...] Na plataforma, assim como em uma sala de aula, não é possível ser anônimo. Isso garante que os relacionamentos que se desenvolvem enquanto você está em um programa da HBX sejam reais, e eles geralmente continuam após a conclusão do programa (tradução livre). Disponível em: https://hbx.hbs.edu/learning-platforms/courseplatform)".

Para desenvolver uma ferramenta com estas características é necessário conhecer bem seu público-alvo. Temos, no entanto, poucas informações sobre o perfil dos estudantes de EAD. No Censo da ABED - Associação Brasileira de Ensino a Distância, o item que fala sobre os alunos é bastante sintético, abordando somente faixa etária, gênero e conciliação entre estudo e trabalho (ABED, 2016, p.56).

\section{Considerações finais}


Retornando à discussão de que a internet promove um novo modo de ler, impulsiona a transformação de habilidades e a construção de saberes, torna-se fundamental estabelecer o perfil de uso do ensino a distância, pelos estudantes, para a definição de estratégias de construção do ambiente virtual. Muitas vezes, as instituições deixam de fazer uso de elementos mais inovadores e interativos por receio de que os alunos não saibam e/ou não consigam acessá-los. Nesse sentido, por não conhecer em detalhe o público-alvo, as instituições de ensino deixam de aproveitar um imenso repertório de dispositivos e ferramentas disponíveis.

No âmbito das transformações no ensino, Pierre Levy nos fornece uma pista que está em diálogo com a proposta aqui delineada. Segundo o autor:

O essencial (...) reside num novo estilo de pedagogia que favoreça, ao mesmo tempo, os aprendizados personalizados e o aprendizado cooperativo em rede. Nesse quadro, o docente vê-se chamado a tornar-se um animador da inteligência coletiva de seus grupos de alunos, em vez de um dispensador direto de conhecimentos (LEVY, 1999, P.36).

A noção, desenvolvida por Levy, de que o docente precisa estar ciente da necessidade de desenvolver um conhecimento cooperativo e ser um animador da inteligência coletiva está ligada a duas dimensões desenvolvidas neste trabalho: a primeira refere-se à necessidade de produção de dados para que as instituições, docentes e tutores conheçam bem seus alunos e possam estabelecer uma estratégia de comunicação, indicando os melhores caminhos aos alunos diante de suas necessidades; a segunda está ligada ao âmbito da hospitalidade, promovendo um ambiente virtual acolhedor e hospitaleiro, que proporcione experiências de troca, reciprocidade e solidariedade entre tutores/professores e alunos, ou mesmo entre colegas, estabelecendo, consequentemente, um vínculo. Outra dimensão importante são os pontos de convergência deste pensamento de Pierre Levy com a metodologia ativa de ensino, que visa promover a proatividade e a cooperação e colaboração entre os participantes (LIMA, 2017).

\section{Referências:}

ABED - Associação Brasileira de Ensino a distância. 2016 - Relatório análitico da aprendizagem a distancia no Brasil. Curitiba: InterSaberes, 2017.

BOURDIEU, P. A Distinção: crítica social do julgamento. São Paulo: Edusp; Porto Alegre, RS: Zouk, 2007 
. O Poder Simbólico. Rio de Janeiro; Bertrand Brasil, 2001.

BULST, N. Sobre o objeto e o método da prosopografia. Politéia: História e Sociedade, Vitória da Conquista, v.5, n.1, p. 47-67, 2005.

CAMARGO, L. O. de L. Hopitalidade. São Paulo: Aleph, 2004.

CAMARGO, L. O. L. Os interstícios da hospitalidade. Revista Hospitalidade, v. 12, n. especial, p. 42-69, 2015.

CANCLINI, N. G. Leitores, espectadores e internautas. São Paulo, lluminuras, 2008.

CASTELLS, M. A Galáxia da Internet. Reflexões sobre a internet, os negócios e a sociedade. Rio de Janeiro, Jorge Zahar Editor, 2003.

GIDDENS, A. Modernidade e Identidade. Rio de Janeiro, Jorge Zahar Editor, 2002.

LASHLEY, C.; LYNCH, P.; MORRISON, A. Hospitality: an introduction. In: Hospitality: a social lens. Oxford: Elsevier, 2007, p. 1-15.

LEVY, P. Cibercultura. São Paulo: Editora 34, 1999.

LIMA, V. V. Espiral construtivista: uma metodologia ativa de ensino-aprendizagem. Interface: COMUNICAÇÃO SAÚDE EDUCAÇÃO. 2017, n.21, v.61.

MONTAGNER, M. A. Trajetórias e biografias: notas para uma análise bourdieusiana. Sociologias, Porto Alegre, ano 9, no 17, jan./jun. 2007, p.240-264.

SANTAELLA, L. Navergar no ciberespaço. O perfil cognitivo do leitor imersivo. São Paulo, Paulus, 2004.

THOMPSON, J. B. A Mídia e a Modernidade. Uma teoria social da mídia. Petrópolis, RJ: Vozes, 1998.

Site acessado: https://hbx.hbs.edu/learning-platforms/course-platform Acesso em 26/04/2018. 